\title{
Advancing teacher technology education using open-ended learning environments as research and training platforms
}

\author{
Eric Poitras \\ University of Utah \\ Tenzin Doleck, Lingyun Huang, Shan Li, Susanne Lajoie \\ McGill University
}

\begin{abstract}
A primary concern of teacher technology education is for pre-service teachers to develop a sophisticated mental model of the affordances of technology that facilitates both teaching and learning with technology. One of the main obstacles to developing the requisite technological pedagogical content knowledge is the inherent challenge faced by teachers in monitoring and controlling certain aspects of their own learning while navigating the web and designing a lesson plan. This paper reviews preliminary findings obtained in our research with nBrowser, an intelligent web browser designed to support pre-service teachers' self-regulated learning and acquisition of technological pedagogical content knowledge. Case examples of data mining techniques are presented that allow the discovery of knowledge regarding pre-service teachers' information-seeking and acquisition behaviours and how to support them. The first case illustrates the use of simulated learner experiments, while the second involves the creation of a model to detect learner behaviours. We discuss the implications in terms of design guidelines recommendations for nBrowser as well as the broader impacts for future research on technological pedagogical content knowledge research and development.
\end{abstract}

\section{Introduction}

Mishra and Koehler (Koehler \& Mishra, 2009; Mishra \& Koehler, 2006) use the term technological pedagogical content knowledge (TPACK) to characterise teachers' knowledge of the integration of technology in the classroom, in particular the relations between content and pedagogy, content and technology, as well as pedagogy and technology. Whereas the later definition refers to the interaction between distinct bodies of knowledge, Angeli and Valanides (2005, 2009, 2013) refer to knowledge about how to transform content and pedagogy through the affordances of technology. This later notion encompasses teachers' competencies, and their abilities to utilise digital representations that augment instruction given the specific characteristics of the students and classroom. In accordance with these views of TPACK, we conceptualise it as a mental model that is built by teachers through an effortful, situated, and personal process, drawing on both their past and future classroom experiences (Calderhead \& Robson, 1991; Niess, 2005; Strauss, 1993).

There are several obstacles to pre-service teachers building sophisticated models of the use of tools and their affordances. Teachers engage in simultaneous activities, requiring their attention before, during, and after classroom instruction. As mentioned by Moos and Pitton (2014), "applying lesson plans that meet the diverse need of students, retrieving content expertise, managing external and internal distractions, identifying verbal and nonverbal cues, monitoring students' level of attention, and assessing students' prior knowledge all demand teachers' attention” (p. 127). Several attempts have been made to design instructional scaffolds as a means to support pre-service teachers in developing more sophisticated mental models related to planning lessons. Scaffolds informed by theories of self-regulated learning (Pintrich, 2000; Winne \& Hadwin, 1998; Zimmerman, 2001) guide pre-service teachers through the cyclical phases of self-regulation, enabling them to understand the task and resources available, plan a lesson, use strategies to translate information into lesson plan edits and revisions, as well as monitor their own progress as a means to make adaptations. Scaffolds can be provided to pre-service teachers by humans, virtual pedagogical agents, or embedded in the context of a learning environment and are progressively faded once they become more competent (Azevedo, 2005; Lajoie \& Azevedo, 2006). For instance, a webbased tool like the Instructional Architect can support teachers in instructional activities design (Recker, Sellers, \& Ye, 2013). Prompts can elicit self-questioning to support teachers in monitoring and controlling certain aspects of their own learning (Kramarski \& Michalsky, 2010, 2013, 2015). A lesson 
plan design scenario can also be created to constrain the amount of choices made by teachers, enabling a system to provide timely and specific feedback (Angeli, Mavroudi, \& Christodoulou, 2015; Angeli, Valanides, Mavroudi, Christodoulou, \& Georgiou, 2015; Mavroudi, Angeli, \& Georgiou, 2013).

The assumption is that through deliberate practice pre-service teachers will become more competent in building and applying mental models pertaining to TPACK in their own classroom practices, allowing them to allocate cognitive resources to other aspects of teaching (Moos \& Pitton, 2014). However, there are important methodological challenges to studying how less and more experienced teachers develop TPACK in both formal and informal learning environments, including higher education and workplace settings (Hofer \& Harris, 2012; Phillips, 2013). There is a growing body of literature that recognises the need to conceptualise lesson planning as an event, using data captured from multiple sources to capture the temporal unfolding of the design process. These methods include but are not limited to expert, self, and peer assessments, as well as interviews, design products, reflections, and portfolios (Angeli \& Valanides, 2009; Harris, Grandgenett, \& Hofer, 2010; Harris \& Hofer, 2009a, 2009b, 2011; Rosenberg, Greenhalgh, \& Koehler, 2015). In this paper, we assert that TPACK research can be advanced through the in-depth examination of frequency, patterns, timing, sequencing, and content of design-related activities captured in the form of trace log data collected in open-ended learning environments. The assumption is that open-ended learning environments can trace learner behaviours, thereby serving as both a research and training platform that complements traditional teacher technology educational programs, interventions, and workshops. We describe nBrowser, an intelligent web browser that can model, track, and foster teachers' self-regulatory processes while navigating the web and designing technology-infused lesson plans. We discuss educational data mining techniques used in studying the mediating role of SRL towards TPACK development and make recommendations for designing adaptive open-ended learning environments that tailor instruction to the specific needs of different teachers.

\section{Technological pedagogical content knowledge}

Over the past decade, a large and growing body of literature has investigated the broad applications of the TPACK framework towards teacher technology education, including the development of teacher professional development programs, training solutions, the evaluation of teacher practices and artifacts as well as the creation of formative/summative assessments (e.g., Chai, Koh, \& Tsai, 2013; Rosenberg \& Koehler, 2015). The term TPACK is broadly used in the research literature to characterise the cognitive structures (declarative knowledge) that are required for teachers to effectively use technology as a means to achieve instructional goals (Koehler \& Mishra, 2009; Mishra \& Koehler, 2006). The TPACK framework describes teachers' knowledge in terms of interactions that occur between three distinct domain areas, namely: (1) content knowledge (i.e., subject matter to be learned or taught); (2) pedagogical knowledge (i.e., practices or methods of teaching and learning); and, (3) technology knowledge (i.e., manner of thinking about or working with technology, tools, and resources) (Graham, 2011). In this paper, the abbreviation TPACK will be used to refer to a mental model (Johnson-Laird, 1980), a form of mental representation corresponding to students' mental states that is manipulated by a teacher and that in turn constrain the goals they pursue in the classroom, and the teaching methods, tools, technologies, and resources that are employed to achieve these goals (Calderhead \& Robson, 1991; Strauss, 1993). The notion of a mental model emphasises the cognitive processes or procedural knowledge involved in understanding technology integration approaches, learning activities, and tool affordances, rather than distinct types of declarative knowledge.

Teachers' knowledge and understanding of tool affordances refers to "how particular topics that are difficult to be understood by learners or difficult to be represented by teachers can be transformed and taught more effectively with technology in ways that signify its added value” (Angeli \& Valanides, 2009, p. 155). Teachers build more sophisticated mental models through an effortful and personal process that involves: (1) perceiving how the actual affordances of tools can be used to transform content into representations conducive to student understanding; (2) tailoring these representations to the specific needs of their students; and, (3) using pedagogical strategies to make use of these representations in the classroom. Teachers' ability to perceive the actual affordances of tools (e.g., record and hear sound) and make explicit connections with content (e.g., auditory representations) and pedagogy (e.g., students can recognise text read aloud, supporting word recognition) progresses along a trajectory towards expertise. Experienced teachers use technology not simply to deliver content, but rather as a means to facilitate student efforts to assimilate, transform, or create information. 
A primary concern of teacher technology education is to determine what expert teachers know about the affordances of tools, and how to support novice teachers to acquire similar competencies (Lajoie, 2003). Recent evidence suggests that novice teachers become acutely aware of their own limited cognitive resources while undergoing pre-service education program internships (Moos \& Pitton, 2014). Preservice teachers are expected to successfully apply lesson plans that meet the diverse needs of students, recall the content that will be taught and students' prior knowledge, manage distractions, and monitor students' level of attention as well as verbal and nonverbal cues. These findings are consistent with those of Angeli and Valanides (2005, 2008) regarding the need to support pre-service teachers in utilising the affordances of technology while planning lessons. In order to successfully integrate technology into instructional planning, Harris and Hofer (2009a) proposed a five-step approach which involves: 1) choose learning goals; 2) make pedagogical decisions; 3) select activity types to combine; 4) select assessment strategies; and, 5) select tools/resources. Furthermore, Harris and Hofer (2009b) suggested that learning activities such as knowledge building activities as well as convergent and divergent knowledge expression activities can function as planning tools to scaffold teachers' TPACK development. Besides, by using the approach of learning by design, teachers can form a comprehensive and situated understanding of technology, thus promoting their professional development (Koehler \& Mishra, 2005). The rationale is for pre-service teachers to develop mental models related to planning lessons using the affordances of technology that become more sophisticated through deliberate practice, enabling cognitive resources to be used in other aspects of teaching. Furthermore, we argue that pre-service teachers' ability to regulate their own learning is required for them to develop TPACK.

\section{Self-regulated learning and TPACK development}

Self-regulated learning (SRL) theories account for the cognitive, affective, metacognitive, and motivational processes that characterise learners' efforts to build sophisticated mental models during learning (Pintrich, 2000; Winne, 2001; Winne \& Hadwin, 1998; Zimmerman, 2000). Learners are selfregulated to the extent that they are actively managing their own learning by evaluating and controlling their efforts (Paris \& Paris, 2001; Pintrich, 2004). According to information-processing models of SRL (Azevedo, 2008; Greene \& Azevedo, 2007; Winne \& Hadwin, 2008, 2010), learners construct mental models in accordance with four distinct phases, wherein learners engage in the following activities: (1) establishing the demands of a task; (2) setting goals and planning their efforts; (3) using strategies to assimilate information; and, (4) adapting their efforts while evaluating the outcomes. In each phase, learners engage in metacognitive monitoring activities by performing cognitive tasks that result in products that are compared against standards. These cognitive evaluations may lead a learner to deploy metacognitive control strategies where learning operations result in refining the product, revising the standards and task conditions, or adjusting the phase objectives.

Research has shown that the monitoring and control of activities that characterise self-regulated learning influence pre-service teachers' acquisition of TPACK (Kramarski \& Michalsky, 2009, 2010). In doing so, we posit that SRL mediates successful task performance in the context of open-ended learning environments, including teachers' efforts to seek and acquire information, construct and refine a solution, and assess its quality (e.g., Segedy, Biswas, \& Sulcer, 2014). As shown in Figure 1, we limit the scope of our research to the examination of how pre-service teachers engage in cognitive and metacognitive activities while developing TPACK by seeking and acquiring information. 


\begin{tabular}{|c|c|c|c|c|}
\hline & Planning & Monitoring & Strategy Use & $\begin{array}{l}\text { Task Difficulty, } \\
\text { Demands, and } \\
\text { Motivation }\end{array}$ \\
\hline $\begin{array}{l}\text { Information- } \\
\text { Seeking }\end{array}$ & \multirow{3}{*}{$\begin{array}{l}\text {-Goal-Setting } \\
\text { (GS) } \\
\text {-Sub-Goal } \\
\text { Setting (SGS) } \\
\text { - Recycle Goal } \\
\text { in WM } \\
\text { (RGWM) } \\
\text {-Prior } \\
\text { Knowledge } \\
\text { Activation } \\
\text { (PKA) }\end{array}$} & $\begin{array}{l}\text {-Content Evaluation } \\
(\mathrm{CE}+/-) \\
\cdot \text { Expectation of } \\
\text { Adequacy of Content } \\
(\mathrm{EAC}+/-)\end{array}$ & $\begin{array}{l}\text {-Selecting New Informational Source } \\
\text { (SNIS) } \\
\text {-Coordinating Informational Source } \\
\text { (COIS) } \\
\text {-Previewing the Content (PC) } \\
\text { - Looking for Specific Information (LSI) } \\
\text {-Anticipating Information (AI) } \\
\text {-Varying Reading Rate (VRR+/-) }\end{array}$ & \multirow[t]{3}{*}{$\begin{array}{l}\text {-Time Management } \\
\text { (TM) } \\
\text {-Task Difficulty (TD+/-) } \\
\text { - Help Seeking } \\
\text { Behaviors (HSB) } \\
\text {-Control of Context } \\
\text { (CC) } \\
\text { - Interest Statement } \\
\text { (INT+/-) }\end{array}$} \\
\hline $\begin{array}{l}\text { Solution } \\
\text { Construction } \\
\text { \& Refinement }\end{array}$ & & $\begin{array}{l}\text {-Feeling of Knowing } \\
\text { (FOK+/-) } \\
\text { - Judgment of } \\
\text { Learning (JOL+/-) } \\
\text { - Monitor Use of } \\
\text { Strategies (MUS) }\end{array}$ & $\begin{array}{l}\text { - Reinstating Information (RI) } \\
\text { - Summarizing Information (SI) } \\
\text {-Verbalizing Information (VI) } \\
\text { - Skipping Information (SI) } \\
\text { - Elaborating Information (EI) } \\
\text { - Highlighting Information (HI) }\end{array}$ & \\
\hline $\begin{array}{c}\text { Solution } \\
\text { Assessment }\end{array}$ & & $\begin{array}{l}\text {-Monitor Progress } \\
\text { Towards Goals } \\
\text { (MPG) } \\
\text {-Monitor Emotional } \\
\text { Reactions (MER) } \\
\text {-Self-Questioning } \\
\text { (SQ) }\end{array}$ & $\begin{array}{l}\text {-Evaluating Information on the Basis } \\
\text { of PK (EIPK+/-) } \\
\text {-Connecting Information with } \\
\text { Current/Past Practice (CICP) } \\
\text {-Connecting Information with Future } \\
\text { Practice (CIFP) } \\
\text {-Connecting Information with Students } \\
\text { (CIS) } \\
\text {-Appraising Information (Al+/-) }\end{array}$ & \\
\hline
\end{tabular}

Figure 1. Pre-service teachers' cognitive and metacognitive activities across SRL phases and tasks that mediate the acquisition of TPACK while designing lesson plans

In order to design a lesson plan, teachers should identify and interpret important information while also evaluating its relevance to the chosen design. This requires a consideration of the amount of resources available to them in designing a lesson plan, the time allocated to do so, and any relevant past experiences or resources. For example, teachers may have only a few hours to prepare and plan an activity for their first grade mathematics class. They begin by setting a broad learning objective for their lesson, to compose and decompose numbers and understand place value (i.e., two-digit number represent amounts of tens and ones). Using a web browser, teachers may activate relevant prior knowledge, and set the goal of navigating to the Open Educational Resources (OER) commons website and use search filters to find relevant resources. They then set a sub-goal to search for online resources that are relevant to achieving the learning objective and disregard irrelevant resources. In doing so, teachers may pursue the sub-goal by using strategies to assimilate information obtained from the website, only later to reinstate and revise the sub-goal as a result of evaluating the products of these efforts. They then begin to plan their efforts by stating and re-instating goals while constructing the lesson plan as well as retrieving relevant information from memory. This process is repeated as teachers' goals are refined and modified while making progress towards the final solution or as they encounter difficulties and impasses along the way. Let us now turn to how this SRL model informs the design and development of an open-ended learning environment that supports novice teachers in regulating their own learning as they acquire technological pedagogical content knowledge.

\section{External regulation of TPACK in open-ended learning environments}

According to Hannafin and colleagues (Hannafin, 1995; Hannafin, Land, \& Oliver, 1999), open-ended learning environments (OELEs) are comprehensive, integrated systems that induce cognitive engagement through problem-based contexts, learner-centered activities, technological tools and resources, and guided exploration. Learners determine what to learn and how to proceed according to their unique needs, beliefs, and understanding (Hannafin, Hall, Land, \& Hill, 1994; Land \& Hannafin, 1996). The resources and tools in OELEs are designed for expanding rather than narrowing the range of individual's understandings and perspectives (Hannafin, 1995). Knowledge is constructed or modified through individual's interactions with the environment (Janette, Susan, Hill, \& Land, 1998). While the opportunities provided by OELEs for promoting learning are considerable, OELEs can be disorienting, even unsettling for learners if they do not receive appropriate assistance, preventing them from planning, exploring, monitoring, and evaluating their own unique learning process (Janette et al., 1998; Lajoie, 
2005). Thus, scaffolding should be one of the basic components of effective and well-designed OELEs (Hannafin et al., 1999). The assumption of scaffolding is that it can support learners to reach their potential by providing necessary tools, strategies, or guides through either human or computer guidance, or both (Lajoie, 2005). At the same time, scaffolds should fade out gradually when learners showed their capability to perform tasks without these external supports.

Researchers have coined the metaphor of metacognitive tools to refer to any type of OELE that dynamically scaffold learners in regulating certain aspects of their own learning that would otherwise be out of their reach (Azevedo, 2005; Lajoie \& Azevedo, 2006; Lajoie \& Poitras, in press). There are several challenges inherent in providing adaptive scaffolding as a means to address the specific needs of different pre-service teachers while learning about conceptually rich domains, such as technological integration to augment teaching and learning. A critical aspect of tailoring the delivery of scaffolds to pre-service teachers is the need to continually capture learner behaviours as a means to prescribe the most suitable instructional content during task performance (Shute \& Zapata-Rivera, 2012). Previous attempts at scaffolding pre-service teachers' SRL as a means to enhance TPACK acquisition while designing lesson plans differed in terms of what process is scaffolded as well as when and how scaffolds are provided to teachers. For instance, Kramarski and Michalsky (2009, 2010) found that the IMPROVE self-questioning method that relies on prompts to foster self-regulatory processes resulted in more sophisticated lesson plan designs in comparison to those without explicit metacognitive supports. Angeli and colleagues (2015, 2015) and Mavroudi et al. (2013) rely on structured lesson plan design scenarios to support preservice teachers design decisions and self-regulation, allowing the system to sequence instructional content and provide timely feedback. However, a systematic understanding of how teachers understand the task of designing technology-infused lesson plans, set goals for learning about the affordances of different technologies, use strategies to search and translate information into lesson plan edits, and monitor their progress as a means to re-adjust their efforts is still lacking. The following section elaborates further on the benefits of OELEs in modelling SRL and improving the adaptive capabilities of instructional scaffolds by drawing examples from our own research with nBrowser.

\section{nBrowser: An OELE that adaptively fosters SRL and TPACK development}

The underlying rationale for the design of the Novessa intelligent web browser (nBrowser) is that it can support pre-service teachers in designing lesson plans, helping them internalise lifelong learning skill that will assist them in their future practice. In doing so, the TPACK model informs the design of scaffolds and assessments as teachers design, enact, and reflect upon the relationships between technology, content, and pedagogy (Mouza \& Karchmer-Klein, 2013). The system scaffolds TPACK acquisition by supporting them as they acquire knowledge of the integration of technology in the classroom while navigating the web and aligning content and pedagogy, content and technology, as well as pedagogy and technology within their chosen designs (Koehler \& Mishra, 2009; Mishra \& Koehler, 2006). The nBrowser provides several features designed as metacognitive tools to support SRL processes described in Figure 1. Contemporary models of SRL (Azevedo, 2008; Winne \& Hadwin, 2008) enable researchers to examine the complex interactions between teacher characteristics, elements of the environment, and the deployment of SRL processes. The nBrowser has four major components that are common to most intelligent tutoring systems: the domain, learner, instructional, and user-interface models (Shute \& Zapata-Rivera, 2012; Sottilare, Graesser, \& Hu, 2013; VanLehn, 2006; Woolf, 2009).

As shown in Figure 2, the nBrowser interface shares several characteristics with OELEs in that preservice teachers are autonomous in respect to their navigation and design choices (Hannafin et al., 1994; Land, 2000; Segedy et al., 2014). Pre-service teachers begin a learning session by either reading a case description (i.e., Solve mode) or designing their own lesson plan (i.e., Create mode). A case will typically describe an issue faced by a practicing teacher where technology may be used to facilitate teaching practices and student learning outcomes. As an example, the case of Linda the math teacher describes her students' reticence to be in front of the class and solve math problems on the board. The goal for the preservice teachers is to design a lesson plan where technology is used to support Linda in addressing the issue. At the bottom of the browser window, a pedagogical agent named Amy is designed to interact with pre-service teachers as a means to track, model, and foster SRL processes during task performance. Amy provides contextualised feedback that assists teachers in their development of TPACK. To support preservice teachers in building a lesson plan, the nBrowser features a set of tools that are available in the Lesson Plan sidebar, which is organised into the following panels: (1) the Lesson Plan Details panel that 
support teachers in setting objectives for their lesson plan designs; (2) the Lesson Plan Assets panel that enables teachers to monitor their progress while navigating the web; and, (3) the Lesson Plan Builder panel that allow teachers to translate online resources, examples, and hints into lesson plan edits. Teachers may navigate the web using the browser window and controls as well as request system recommendations for both online resources and example lesson plans. The system recommendations are delivered on the basis of a computational representation where online resources are represented as nodes interrelated through different semantic relations, allowing nBrowser to analyse and update properties of the network. In doing so, the system implements a network-based approach to learner modeling that is used to tailor instruction to the specific needs of different pre-service teachers (for review, see Poitras \& Fazeli, 2016a). The following section reviews how trace log data is collected with nBrowser and analysed to iteratively improve scaffolds targeting pre-service teachers' information seeking and acquisition.

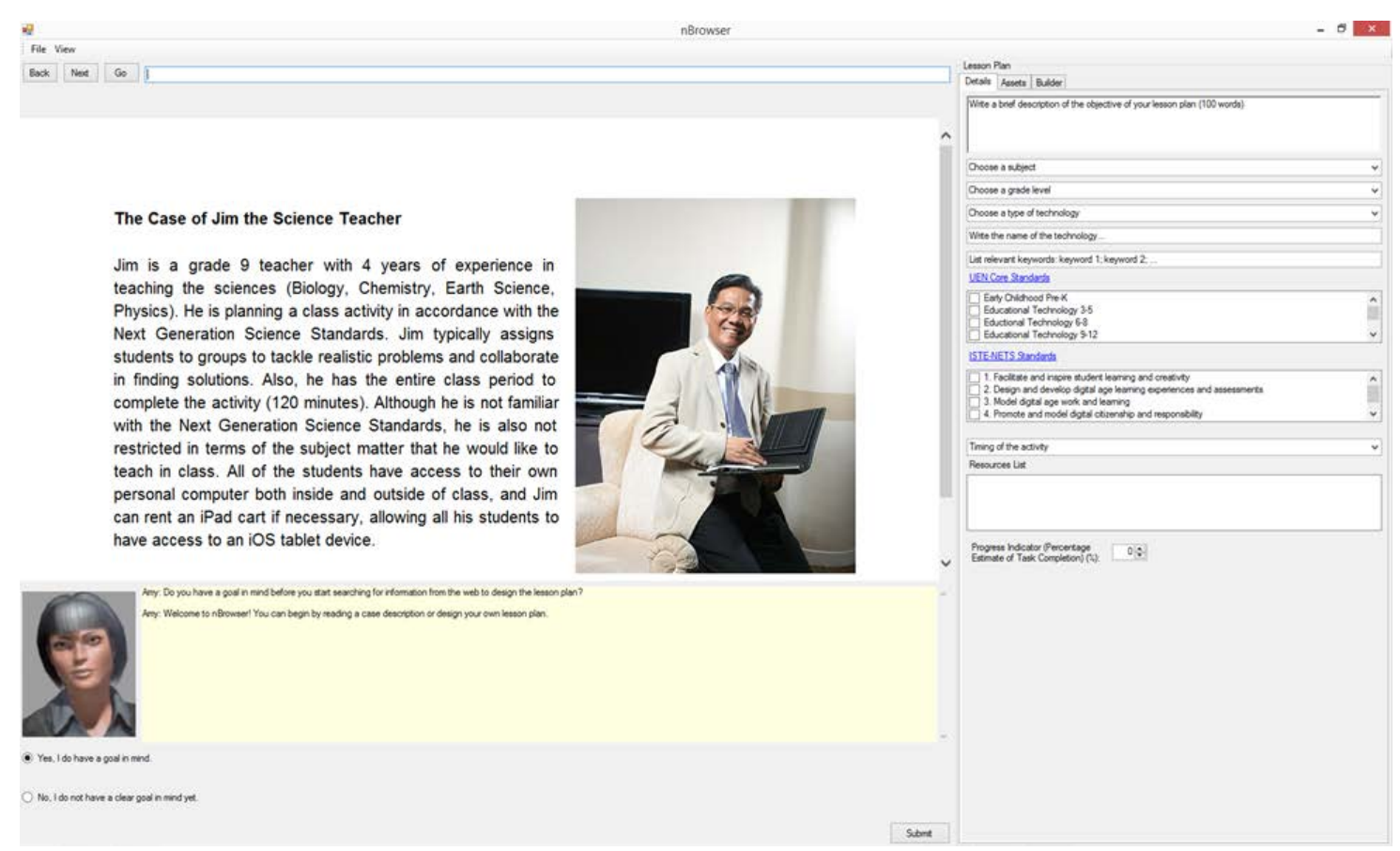

Figure 2. nBrowser user interface

\section{Modeling SRL and TPACK acquisition with nBrowser}

The design and evaluation of nBrowser scaffolds to support pre-service teachers' information-seeking and acquisition about lesson planning using technology has thus far been limited to testing the convergence effect. The convergence effect introduced by Poitras and Fazeli (2016a) pertains to the situation that occurs when multiple learners concur on their ratings of the usefulness of an online resource. nBrowser relies on a computational representation, consisting of nodes that represent online resources, which are interrelated through links weighed on the basis of intertextual relationships. The cosine similarity of each pair of online resources is a dimension or type of relationship used to determine topic similarity based on the amount of co-occurring words mentioned in the documents. According to the convergence effect, the nBrowser is hypothesised to converge the network of online resources towards an optimal state as learners rate the usefulness of online resources. Our research addressed the following questions pertaining to the convergence effect:

1. How does a network converge to an optimal state as learners rate the usefulness of online resources?

2. What factors influence the rate of network convergence?; and

3. How can the convergence process be optimised by a system?

In addressing these questions, the nBrowser recommender engine is expected to become more efficient in converging a network to an optimal state, enabling the system to suggest online resources to learners that pertain to the most useful topics. The nBrowser system is thus used as a research and training platform, 
allowing researchers to collect detailed log trace data as pre-service teachers' interact with the user interface and design their own lesson plan. In the following subsections, we elaborate further on the methodological and analytical approaches used to test the convergence effect.

\section{Methodological techniques}

A total of 68 students (male $=15$ [22\%], female $=53$ [78\%]) enrolled in the research participant pool of the Department of Educational Psychology at a western US public university participated in this study for partial course credit. Less than half of the students were enrolled or had completed a practicum experience in an actual classroom (46\%) and on average had spent 2 years studying in their respective programs ( $S D=1.0$, range: $1-6)$. The students were randomly assigned to either one of two experimental conditions: (1) a static version of nBrowser, where the network was not allowed to converge to an optimal arrangement through the spreading activation algorithm; and (2) a dynamic version of nBrowser, where the network was allowed to converge to an optimal state. The design guidelines of the nBrowser interface were otherwise identical, and students were unaware of what conditions they were assigned to prior to completing the study.

The study was conducted over a one-hour session for each student. All students used nBrowser on the same computer. The experimental instructions consisted of a short video on the monitor that explained the nBrowser interface and the learning goal. Students were given 30 minutes to learn about technological integration by navigating the web and designing a lesson plan that solved the case of Linda the math teacher, who complained about students' shyness and anxiety when solving math equations in front of class. In this manner, teachers were given opportunities to use their competencies, and their abilities to utilise digital representations that enhance instruction, in conjunction with their understanding of the specific characteristics of the students Angeli and Valanides (2005, 2009, 2013). During the learning session, students were permitted to navigate the web using nBrowser to design their own lesson plan and resolve the issue identified in the teacher case.

\section{Analytical techniques}

Recent advances in educational data mining allow researchers to discover novel information from the fine-grained information obtained in trace log data collected in OELEs (Baker, 2010; Baker \& Yacef, 2009; Desmarais \& Baker, 2012; Romero \& Ventura, 2010; Romero, Ventura, Pechenizkiy, \& Baker, 2010). The raw trace log data obtained from nBrowser was filtered and aggregated to facilitate interpretation of learner behaviours. We review two cases where the log data of learner behaviours was analysed in different ways to investigate the convergence effect. The first line of research examined the nBrowser log data in terms of the incidence of behaviours that are indicative of information-seeking and acquisition as a means to simulate them to examine the performance of the recommender system. The simulated learner experiment allows emulating these behaviours under controlled conditions while manipulating and observing factors that may influence the convergence process (i.e., research questions 1 and 2). The second line of research extracted information from the log data to train and evaluate a predictive model that allows the system to infer the usefulness of online resources when learners fail to report ratings. In doing so, the predictive model stands to improve the efficiency of the system in terms of converging a network to an optimal state (i.e., research question 3).

\section{Simulating pre-service teachers' information-seeking behaviours}

Recent efforts to address the first and second research questions have relied on computer simulations to study the rate of network convergence while manipulating the algorithm that allows a system to spread activation through the network as well as other relevant factors such as the amount of nodes featured in the network. Simulation-based methods are an emerging area of research in the learning sciences (Champaign \& Cohen, 2013; McCalla \& Champaign, 2013; Poitras \& Fazeli, 2016b; VanLehn, Ohlsson, \& Nason, 1994). Although simulations can be conducted under various conditions, one method involves a node or online resource within the network that is pre-determined for evaluation purposes to be the most useful to pre-service teachers' efforts to design a lesson plan. The remaining nodes in the network serve as a comparison. The simulation model emulates as closely as possible actual behaviours observed in human learners, including parameters validated in previous studies (Poitras \& Fazeli, 2017a) that capture the total number of sites visited by pre-service teachers as well as the probability of requesting a system 
recommendation, visiting a system suggested site, and submitting a rating. The convergence process observed during the simulation is examined in terms of the resulting node weights and system recommendations. The assumption is that the revised spreading activation algorithm should allow the recommender system to suggest the most useful resource as the network converges towards the nodes rated by the simulated learners. On the question of the node-weighing scheme, a simulation conducted with 100 simulated learners and a small network that included 10 nodes found that the recommender system suggested the most useful online resource 1.76 times more often than the comparison nodes (Poitras \& Fazeli, 2017a). The network was observed to converge towards the node following the 28th simulated learner session, at which time the system repeatedly directed future learners towards the most useful online resource. In sum, the method allows researchers to iteratively improve the network-based learner model by studying the impacts of manipulations to the underlying algorithms under controlled conditions based on information obtained from log data.

\section{Modeling pre-service teachers' information-seeking behaviours}

In addressing the third research question, how can the convergence process be optimised by a system, we mined the log trace data collected from pre-service teachers to train and test predictive models (Poitras \& Fazeli, 2017b). The usefulness property of a node within the network is continually updated by nBrowser based on the self-reported ratings submitted by the teachers. It stands to reason that the rate of network convergence may be optimised by predicting the ratings based on other observable indicators when teachers either fail to submit a rating or are unreasonably positive in their evaluations (i.e., low response rate and social desirability). In this manner, we do not rely on self-report data entirely. Using an induction-rule mining approach (Cohen, 1995), we extracted several features from the log data obtained from 68 learners, including the elapsed time on the site, the panel selections, count of lesson plan edits, and the total amount of page visits during the session. Furthermore, the log file was aggregated at the level of site navigation events and filtered for sites where a rating was actually submitted, resulting in 70 examples in the dataset. Decision rules were induced to predict the valence of ratings (i.e., positive or negative) based on the features extracted from the log data using a ten-fold cross-validation procedure. The model was trained using $90 \%$ of the examples, and then tested using the remaining $10 \%$ of the data. This process was repeated for each of the ten partitions of the example set. We also optimised the conditional rules for several parameters and discretised the continuous features into nominal features by varying the ranges from 2 to 20 bins. Using a total of 15 bins for the feature discretisation step, the most accurate rule set achieved an average classification accuracy of $69 \%$ in predicting both positive and negative ratings submitted by teachers (Poitras \& Fazeli, 2017b). The resulting rule set can be implemented as part of the network-based learner model to continually update the usefulness property of nodes, thereby improving the efficiency of the convergence process and the resulting system recommendations of online resources. Having explained the benefits of trace log data to model preservice teachers' information-seeking behaviours while navigating the web with nBrowser, we will now discuss the broader implications for understanding and developing TPACK.

\section{Implications and future directions for TPACK research and development}

These findings have direct implications in fostering teachers' acquisition of TPACK. Teachers consider a broad range of potential classroom activities while designing their lessons and attempt to integrate the affordances of a particular technology to support pedagogical practices and student understanding. The nBrowser system supports teachers in learning about the affordances of novel technologies by scaffolding their efforts to seek and acquire information while navigating the web for online resources. These studies aim to improve the ability of the nBrowser recommender system to deliver the most useful online resources for teachers to consider. In solving the case of Linda, the math teacher, for instance, teachers may learn about students who documented their own problem-solving using a video creation software and made available the video clips on YouTube. Others may design a lesson using a website that enables students to solve math problems and receive feedback. As future teachers use the nBrowser system, researchers are able to examine the log trace data to continually improve how the system learns from their behaviours and adapts itself to their specific needs and interests.

Although extensive research has been carried out on TPACK development in tertiary education, researchers have not treated trace data in much detail. Trace log data, such as event traces and recordings 
collected in the context of OELEs, are commonly used methodologies in usability testing and data mining in the field of computer human interaction. The methodology is especially critical in modeling the deployment of SRL processes that mediate teachers' acquisition of TPACK, allowing for fine-grained records of frequency of events, patterns of activities, the timing and sequencing of events, as well as the analysis of the content of unstructured events, such as notes, summaries, and lesson plan edits (Azevedo et al., 2013; Hadwin, Nesbit, Jamieson-Noel, Code, \& Winne, 2007; Kinnebrew, Loretz, \& Biswas, 2013; Schraw, 2007, 2010; Winne, 2010). We have demonstrated how trace data can be used to analyse how TPACK evolves dynamically. More importantly we demonstrate how trace data can be used to scaffold SRL processes that mediate the acquisition of TPACK. The preliminary findings obtained from mining the log data of nBrowser enables researchers to improve the ability of the system to identify the most useful online resources for lesson planning and deliver them to teachers. In doing so, teachers gain access to the most helpful materials during instructional planning. The performance of the recommender system can be further improved by manipulating the algorithms while simulating how a teacher typically behaves with nBrowser. This is especially useful in making modifications to the recommender system for large collections of online resources for teachers to consider, where an experimental approach with actual human learners would be too labor intensive to be feasible in practice.

While OELEs provide flexible and personalised learning experiences for pre-service teachers to improve their TPACK development, there are several limitations owing to the characteristics of OELEs and the complexity of TPACK. Firstly, OELEs are learner-centered, technology-based environments that require sophisticated levels of cognitive management (Land, 2000). Different from traditional environments, preservice teachers will have to allocate more cognitive resources to plan, create, monitor, and evaluate their own progress. Some may feel frustrated since novices often lack the prerequisite SRL skills to fully engage in OELEs (Biswas, Segedy, \& Kinnebrew, 2013). Secondly, OELEs allow for teachers to be autonomous and creative in their navigation and design-related decisions, ensuring that the task is illstructured and open-ended. These design guidelines entail important challenges for learner modeling, as teachers may choose to pursue different goals and navigational trajectories that may not be anticipated by system designers. The challenge is to design comprehensive and flexible learner models that enable OELEs to deliver scaffolds that are scalable to a broad range of instructional situations. Lastly, trace log data provide important insights into pre-service teachers' SRL deployment and TPACK development. The extent to which relevant constructs from these models are reliably and comprehensively captured through the sensors that provide data to the learner model is problematic and requires extensive research and development. There is a need to prioritise what constructs to assess and examine the types of sensors that are required for the system to produce both valid and reliable inferences. Once these benchmarks are established empirical studies can be conducted to assess teachers' development of TPACK using nBrowser. In particular, we can look more closely at teachers' mental model development as they plan their lessons in an effortful and situated manner, linking their knowledge to these new experiences and drawing on both their past and future classroom experiences (Calderhead \& Robson, 1991; Niess, 2005; Strauss, 1993).

Notwithstanding our preliminary findings with nBrowser, further research should be undertaken to investigate the nature and development of TPACK using educational data mining techniques to analyse trace log data collected in OELEs. We call on researchers to utilise the affordances of log data as a tool in their investigations of the development of TPACK in pre- and in-service teachers. The limitations identified in the earlier subsections provide an immediate pathway for future research. Scaffolding has emerged as an important dimension in learning in OELEs; thus, a key challenge is to study the relevant benefits of different scaffolding strategies (Hannafin, 1995; Segedy, Kinnebrew, \& Biswas, 2012), and improve mechanisms - around such functioning — for facilitating learning. Trace log data can provide important insights into the impacts of scaffolds moments after their delivery that can complement other methodologies such as the findings obtained from coding lesson plan quality or teacher interviews (e.g., Angeli \& Valanides, 2009; Harris et al., 2010; Harris \& Hofer, 2009a, 2009b 2011; Rosenberg et al., 2015). For instance, our current research with nBrowser has focused heavily on the recommender system embedded in the web browser to facilitate information seeking and acquisition. Several questions remain unanswered at present, most notably the pre-service teachers' navigational trajectories and how their paths map onto either: (1) the networks of online resources crawled and represented in nBrowser, or (2) to those of more experienced in-service teachers using nBrowser to design their own lesson plans. Such studies may reveal where novice teachers need more assistance in developing TPACK. For example, when integrating technology into lesson plans, do teachers need more assistance with the lesson content, 
the integration of technology to represent the content, or the consideration of relevant student characteristics?

Further studies, which take these variables into account not solely to inform system recommendations of online resources and artifacts, but also to directly support designing lesson plans through prompts and hints, will need to be undertaken. Future research should explore the significant potential of improving our understanding of the development of TPACK using log trace data to understand how teachers comment and rate the usefulness or quality or resources as they upload lessons to public repositories (Lee et al., 2015; Recker, 2016) and choose a learning activity for use in their own classrooms (Harris, Hofner et al., 2010). The nBrowser environment serves as a platform to conduct such research as teachers navigate through organised collections of resources and materials. Teachers make decisions to use particular technologies in support of learning activities given a specific subject matter and student population, and trace log data may provide important insights into the behaviours that characterise these decisions and their outcomes. Given the benefits of trace methodologies highlighted in this paper, ensuring that OELEs serve as both research and training platforms to better understand the nature and development of SRL should be a priority for advancing future TPACK scholarship.

\section{References}

Angeli, C., Mavroudi, A., \& Christodoulou, A. (2015a). e-TPCK: An adaptive e-learning technology for the development of teachers' technological pedagogical content knowledge. Proceedings of the Society for Information Technology \& Teacher Education International Conference (Vol. 2015, No. 1, pp. 3059-3064). Chicago, IL.

Angeli, C., \& Valanides, N. (2005). Preservice elementary teachers as information and communication technology designers: An instructional systems design model based on an expanded view of pedagogical content knowledge. Journal of Computer Assisted Learning, 21(4), 292-302. https://doi.org/10.1111/j.1365-2729.2005.00135.x

Angeli, C., \& Valanides, N. (2008, March). TPCK in pre-service teacher education: Preparing primary education students to teach with technology. Paper presented at the Annual Meeting of the America Educational Research Association, New York, NY.

Angeli, C., \& Valanides, N. (2009). Epistemological and methodological issues for the conceptualization, development, and assessment of ICT-TPCK: Advances in technological pedagogical content knowledge (TPCK). Computers \& Education, 52(1), 154-168. https://doi.org/10.1016/j.compedu.2008.07.006

Angeli, C., \& Valanides, N. (2013). Technology mapping: An approach for developing technological pedagogical content knowledge. Journal of Educational Computing Research, 48(2), 199-221. https://doi.org/10.2190/EC.48.2.e

Angeli, C., Valanides, N., Mavroudi, A., Christodoulou, A., \& Georgiou, K. (2015b). Introducing eTPCK: An adaptive e-learning technology for the development of teachers' technological pedagogical content knowledge. In C. Angeli \& N Valanides (Eds.), Technological pedagogical content knowledge (pp. 305-317). New York, NY: Springer. https://doi.org/10.1007/978-1-4899-8080-9_16

Azevedo, R. (2005). Using hypermedia as a metacognitive tool for enhancing student learning? The role of self-regulated learning. Educational Psychologist, 40(4), 199-209. https://doi.org/10.1207/s15326985ep4004_2

Azevedo, R. (2008). The role of self-regulation in learning about science with hypermedia. In D. Robinson \& G. Schraw (Eds.), Recent innovations in educational technology that facilitate student learning (pp. 127-156). Charlotte, NC: Information Age Publishing.

Azevedo, R., Harley, J., Trevors, G., Duffy, M., Feyzi-Behnagh, R., Bouchet, F., \& Landis, R. (2013). Using trace data to examine the complex roles of cognitive, metacognitive, and emotional selfregulatory processes during learning with multi-agent systems. In R. Azevedo, \& V. Aleven (Eds.), International handbook of metacognition and learning technologies (pp. 427-449). Amsterdam, Netherlands: Springer-Verlag. https://doi.org/10.1007/978-1-4419-5546-3_28

Baker, R. S. J. D. (2010). Mining data for student models. In R. Nkmabou, R. Mizoguchi, \& J. Bourdeau (Eds.), Advances in intelligent tutoring systems (pp. 323-338). Secaucus, NJ: Springer. https://doi.org/10.1007/978-3-642-14363-2_16

Baker, R. S. J. D., \& Yacef, K. (2009). The state of educational data mining in 2009: A review and future visions. Journal of Educational Data Mining, 1(1), 3-17. 
Biswas, G., Segedy, J. R., \& Kinnebrew, J. S. (2013). Smart open-ended learning environments that support learners' cognitive and metacognitive processes. Proceedings of the 1st IEEE International Conference on Human Factors in Computing \& Informatics. Maribor, Slovenia. https://doi.org/10.1007/978-3-642-39146-0_27

Calderhead, J., \& Robson, M. (1991). Images of teaching: Student teachers' early conceptions of classroom practice. Teaching \& Teacher Education, 7(1), 1-8. https://doi.org/10.1016/0742051X(91)90053-R

Chai, C.-S., Koh, J. H.-L., \& Tsai, C.-C. (2013). A review of technological pedagogical content knowledge. Educational Technology \& Society, 16(2), 31-51.

Champaign, J., \& Cohen, R. (2013). Ecological content sequencing: from simulated students to an effective user study. International Journal of Learning Technology, 8(4), 337-361. https://doi.org/10.1504/IJLT.2013.059130

Cohen, W. W. (1995). Fast effective rule induction. Proceedings of the twelfth international conference on machine learning (pp. 115-123). California, CA: Kaufman. https://doi.org/10.1016/b978-1-55860377-6.50023-2

Desmarais, M. \& Baker, R. (2012). A review of recent advances in learner and skill modeling in intelligent learning environments. User Modeling And User-Adapted Interaction, 22(1-2), 9-38. https://doi.org/10.1007/s11257-011-9106-8

Graham, C. R. (2011). Theoretical considerations for understanding technological pedagogical content knowledge (TPACK). Computers \& Education, 57(3), 1953-1960. https://doi.org/10.1016/j.compedu.2011.04.010

Greene, J. \& Azevedo, R. (2007). A theoretical review of Winne and Hadwin's model of self-regulated learning: New perspectives and directions. Review of Educational Research, 77(3), 334-372. https://doi.org/10.3102/003465430303953

Hadwin, A. F., Nesbit, J. C., Jamieson-Noel, D., Code, J., \& Winne, P. H. (2007). Examining trace data to explore self-regulated learning. Metacognition and Learning, 2(2-3), 107-124. https://doi.org/10.1007/s11409-007-9016-7

Hannafin, M. J. (1995). Open-ended learning environments: Foundations, assumptions, and implications for automated design. In R. D. Tennyson, \& A. E. Barron (Eds.), Automating instructional design: Computer-based development and delivery tools (pp. 101-129). Berlin: Springer. https://doi.org/10.1007/978-3-642-57821-2_5

Hannafin, M. J., Hall, C., Land, S., \& Hill, J. (1994). Learning in open-ended environments: assumptions, methods, and implications. Educational Technology, 34(8), 48-55.

Hannafin, M. J., Land, S. M., \& Oliver, K. M. (1999). Open learning environments: Foundations, methods, and models. In R. Charles (Ed.), Instructional-design theories and models (pp. 115-140). London: Erlbaum.

Harris, J., Grandgenett, N., \& Hofer, M. (2010). Testing a TPACK-based technology integration assessment rubric. In C. D. Maddux (Ed.), Research highlights in technology and teacher education 2010 (pp. 323-331). Chesapeake, VA: AACE.

Harris, J., \& Hofer, M. (2009a). Grounded tech integration: An effective approach based on content, pedagogy, and teacher planning. Learning \& Leading with Technology, 37(2), 22-25.

Harris J., \& Hofer M. (2009b). Instructional planning activity types as vehicles for curriculum-based TPACK development. In C. D. Maddux (Ed.), Research highlights in technology and teacher education (pp. 99-108). Chesapeake, VA: Society for Information Technology in Teacher Education (SITE).

Harris, J. B., \& Hofer, M. J. (2011). Technological pedagogical content knowledge (TPACK) in action: A descriptive study of secondary teachers' curriculum-based, technology-related instructional planning. Journal of Research on Technology in Education, 43(3), 211-229. https://doi.org/10.1080/15391523.2011.10782570

Harris, J. B., Hofer, M. J., Schmidt, D. A., Blanchard, M. R., Young, C. Y., Grandgenett, N. F., Olphen, M. V. (2010). "Grounded" technology integration: Instructional planning using curriculum-based activity type taxonomies. Journal of Technology and Teacher Education, 18(4), 573-605.

Hofer, M. \& Harris, J. (2012). TPACK research with inservice teachers: Where's the TCK?. In P. Resta (Ed.), Proceedings of Society for Information Technology \& Teacher Education International Conference 2012 (pp. 4704- 4709). Chesapeake, VA: AACE.

Janette, R., Susan, M., Hill, J. R., \& Land, S. M. (1998). Open-ended learning environments: A theoretical framework and model for design. Proceedings of Selected Research and Development 
Presentations at the National Convention of the Association for Educational Communications and Technology (pp. 167-178), St. Louis, MO.

Johnson-Laird, P. N. (1980). Mental models in cognitive science. Cognitive science, 4(1), 71-115. https://doi.org/10.1207/s15516709cog0401_4

Kinnebrew, J. S., Loretz, K. M., \& Biswas, G. (2013). A contextualized, differential sequence mining method to derive students' learning behavior patterns. Journal of Educational Data Mining, 5(1), 190219.

Koehler, M. J., \& Mishra, P. (2005). Teachers learning technology by design. Journal of Computing in Teacher Education, 21(3), 94-102. https://doi.org/10.1.1.130.7937

Koehler, M. J., \& Mishra, P. (2009). What is technological pedagogical content knowledge. Contemporary Issues in Technology and Teacher Education, 9(1), 60-70.

Kramarski, B., \& Michalsky, T. (2009). Three metacognitive approaches to training pre-service teachers in different learning phases of technological pedagogical content knowledge. Educational Research and Evaluation, 15(5), 465-485. https://doi.org/10.1080/13803610903444550

Kramarski, B., \& Michalsky, T. (2010). Preparing preservice teachers for self-regulated learning in the context of technological pedagogical content knowledge. Learning and Instruction, 20(5), 434-447. https://doi.org/10.1016/j.learninstruc.2009.05.003

Kramarski, B., \& Michalsky, T. (2013). Student and teacher perspectives on IMPROVE self-regulation prompts in web-based learning. In International handbook of metacognition and learning technologies (pp. 35-51). New York, NY: Springer. https://doi.org/10.1007/978-1-4419-5546-3_3

Kramarski, B., \& Michalsky, T. (2015). Effect of a TPCK-SRL model on teachers' pedagogical beliefs, self-efficacy, and technology-based lesson design. In C. Angeli \& N Valanides (Eds.), Technological Pedagogical Content Knowledge (pp. 89-112). New York, NY: Springer. https://doi.org/10.1007/9781-4899-8080-9_5

Lajoie, S. P. (2003). Transitions and Trajectories for Studies of Expertise. Educational Researcher, 32(8), 21-25. https://doi.org/10.3102/0013189X032008021

Lajoie, S. P. (2005). Extending the Scaffolding Metaphor. Instructional Science, 33(5-6), 541-557. https://doi.org/10.1007/s11251-005-1279-2

Lajoie, S. P., Azevedo, R. (2006). Teaching and learning in technology-rich learning environments. In P. Alexander \& P. Winne (Eds.), Handbook of educational psychology (pp. 803-821). Mahwah, NJ: Erlbaum.

Lajoie, S. P., Poitras, E. (in press). Crossing disciplinary boundaries to improve technology rich learning environments. Teachers College Record.

Land, S. M. (2000). Cognitive requirements for learning with open-ended learning environments. Educational Technology Research and Development, 48(3), 61-78. https://doi.org/10.1007/BF02319858

Land, S. M., \& Hannafin, M. J. (1996). A conceptual framework for the development of theories-inaction with open-ended learning environments. Educational Technology Research and Development, 44(3), 37-53. https://doi.org/10.1007/BF02300424

Lee, J., Recker, M., Choi, H., Hong, W., Kim, N., \& Lee, K., ... Walker, A. (2015). Applying data mining methods to understand user interactions within learning management systems: Approaches and lessons learned. Journal of Educational Technology Development and Exchange, 8(2). https://doi.org/10.18785/jetde.0802.06

Mavroudi, A., Angeli, C., Georgiou, K. (2013). An e-learning adaptive system for teaching teachers how to teach with technology: A perspective from technological pedagogical content knowledge. In 2nd International Workshop on Teaching Analytics, Leuven, Belgium, 1-3.

McCalla, G., \& Champaign, J. (2013). Simulated Learners. IEEE Intelligent Systems, 28(4), 0067-71. https://doi.org/10.1109/MIS.2013.116

Mishra, P., \& Koehler, M. J. (2006). Technological pedagogical content knowledge: A framework for teacher knowledge. Teachers College Record, 108(6), 1017-1054. https://doi.org/10.1111/j.1467$\underline{9620.2006 .00684 . x}$

Moos, D. C., \& Pitton, D. (2014). Student teacher challenges: Using the cognitive load theory as an explanatory lens. Teaching Education, 25(2), 127-141. https://doi.org/10.1080/10476210.2012.754869

Mouza, C., \& Karchmer-Klein, R. (2013). Promoting and assessing pre-service teachers' technological pedagogical content knowledge (TPACK) in the context of case development. Journal of Educational Computing Research, 48(2), 127-152. https://doi.org/10.2190/EC.48.2.b 
Niess, M. L. (2005). Preparing teachers to teach science and mathematics with technology: Developing a technology pedagogical content knowledge. Teaching and Teacher Education, 21(5), 509-523. https://doi.org/10.1016/j.tate.2005.03.006

Paris, S. G., \& Paris, A. H. (2001). Classroom applications of research on self-regulated learning. Educational Psychologist, 36(2), 89-101. https://doi.org/10.1207/S15326985EP3602_4

Phillips, M. (2013). Investigating in-service teachers' workplace TPACK development. Australian Educational Computing, 28(2), 1-10.

Pintrich, P. R. (2000). The role of goal orientation in self-regulated learning. In M. Boekaerts, P. R. Pintrich, \& M. Zeidner (Eds.), Handbook of self-regulation (pp.451-502). San Diego, CA: Academic Press. https://doi.org/10.1016/B978-012109890-2/50043-3

Pintrich, P. R. (2004). A conceptual framework for assessing motivation and self-regulated learning in college students. Educational Psychology Review, 16(4), 385-407. https://doi.org/10.1007/s10648004-0006-X

Poitras, E., \& Fazeli, N. (2016a). Mining the edublogosphere to enhance teacher professional development. In Shalin Hai-Jew (Ed.), Social media data extraction and content analysis. Hershey, PA: IGI Global.

Poitras, E. \& Fazeli, N. (2016b). Using an intelligent web browser for teacher professional development: Preliminary findings from simulated learners. In G. Chamblee, \& L. Langub (Eds.), Proceedings of Society for Information Technology \& Teacher Education International Conference 2016 (pp. 30373041). Chesapeake, VA: AACE.

Poitras, E. G., Fazeli, N. (2017a). Simulating preservice teachers' information-seeking behaviors while learning with an intelligent web browser. Paper to be presented at the 2017 Society for Information Technology and Teacher Educational Annual Conference. Austin, TX.

Poitras, E. G., \& Fazeli, N. (2017b). Modeling information-seeking behaviors during learning from hypermedia with nBrowser. Paper to be presented at the 2017 American Educational Research Association Annual Meeting. San Antonio, TX.

Recker, M. (2016). Approaches for teacher professional development: The case of the instructional architect. In T. Norton (Ed.), Professional development: Recent advances and future directions. New York, NY: Nova.

Recker, M., Sellers, L., \& Ye, L. (2013). Teacher design using online learning resources: A comparative case study of science and mathematics teachers. Education Research International, 2013, 1-11. https://doi.org/10.1155/2013/243248

Romero, C., \& Ventura, S. (2010). Educational data mining: A review of the state of the art. IEEE Transactions on Systems, Man, and Cybernetics, Part C (Applications and Reviews), 40(6), 601-618. https://doi.org/10.1109/TSMCC.2010.2053532

Romero, C., Ventura, S., Pechenizkiy, M., Baker, R.S.J.d. (2010) Introduction. In C. Romero, S. Ventura, M. Pechenizkiy, R. S. J. d. Baker (Eds.) Handbook of educational data mining (pp. 1-8). Boca Raton, FL: CRC Press. https://doi.org/10.1201/b10274-2

Rosenberg, J. M., Greenhalgh, S. P., \& Koehler, M. J. (2015). A performance assessment of teachers' TPACK using artifacts from digital portfolios. In D. Rutledge \& D. Slykhuis (Eds.), Proceedings of Society for Information Technology \& Teacher Education International Conference 2015 (pp. 33903397). Chesapeake, VA: AACE.

Rosenberg, J. M., \& Koehler, M. J. (2015). Context and technological pedagogical content knowledge (TPACK): A systematic review. Journal of Research on Technology in Education, 47(3), 186-210. https://doi.org/10.1080/15391523.2015.1052663

Schraw, G. (2007). The use of computer-based environments for understanding and improving selfregulation. Metacognition and Learning, 2(2-3), 169-176. https://doi.org/10.1007/s11409-007-9015-8

Schraw, G. (2010). Measuring self-regulation in computer-based learning environments. Educational Psychologist, 45(4), 258-266. https://doi.org/10.1080/00461520.2010.515936

Segedy, J. R., Biswas. G., \& Sulcer, B. (2014). A model-based behavior analysis approach for openended environments. Educational Technology \& Society, 17(1), 272-282.

Segedy, J. R., Kinnebrew, J., \& Biswas, G. (2012). The effect of contextualized conversational feedback in a complex open-ended learning environment. Educational Technology Research and Development, 61(1), 71-89. https://doi.org/10.1007/s11423-012-9275-0

Shute, V. J., \& Zapata-Rivera, D. (2012). Adaptive educational systems. In P. Durlach, \& A. Lesgold (Eds.), Adaptive technologies for training and education (pp. 2-27). New York, NY: Cambridge University Press. https://doi.org/10.1017/CBO9781139049580.004 
Sottilare, R., Graesser, A., Hu, X., \& Holden, H. (2013). Design recommendations for intelligent tutoring systems: Learner modeling (Vol.1). Orlando, FL: Army Research Laboratory.

Strauss, S. (1993). Teachers' pedagogical content knowledge about children's minds and learning: Implications for teacher education. Educational Psychologist, 28(3), 279-290. https://doi.org/10.1207/s15326985ep2803_7

VanLehn, K. (2006). The behavior of tutoring systems. International Journal of Artificial Intelligence in Education, 16(3), 227-265.

VanLehn, K., Ohlsson, S., \& Nason, R. (1994). Applications of simulated students: An exploration. Journal of Artificial Intelligence in Education, 5(2), 135-175.

Winne, P. H. (2001). Self-regulated learning viewed from models of information processing. In B. J. Zimmerman \& D. H. Schunk (Eds.), Self-regulated learning and academic achievement (pp. 153190). New York, NY: Erlbaum.

Winne, P. H. (2010). Improving measurements of self-regulated learning. Educational Psychologist, 45(4), 267-276. https://doi.org/10.1080/00461520.2010.517150

Winne, P. H., Hadwin, A. F. (1998). Studying as self-regulated learning. In D.J. Hacker, J. Dunlosky, \& A. C. Graesser (Eds.), Metacognition in educational theory and practice (pp. 277-304). Mahwah, NJ: Erlbaum.

Winne, P. H., \& Hadwin, A. F. (2008). The weave of motivation and self-regulated learning. In D. H. Schunk \& B. J. Zimmerman (Eds.), Motivation and self-regulated learning: Theory, research and applications (pp. 298-314). New York, NY: Erlbaum.

Winne, P. H., \& Hadwin, A. F. (2010). Self-regulated learning and sociocognitive theory. In P. Peterson, E. Baker \& B. McGaw (Eds.), International encyclopedia of education (pp. 503-508). Amsterdam: Elsevier. https://doi.org/10.1016/B978-0-08-044894-7.00470-X

Woolf, B. (2009) Building intelligent interactive tutors: Student-centered strategies for revolutionizing elearning. San Francisco, CA: Elsevier Inc., Morgan Kauffman.

Zimmerman, B. J. (2000). Attaining self-regulation: A social cognitive perspective. In M. Boekaerts, P. R. Pintrich, \& M. Zeidner (Eds.), Handbook of self-regulation (pp. 13-39). New York, NY: Academic Press. https://doi.org/10.1016/B978-012109890-2/50031-7

Zimmerman, B. J. (2001). Theories of self-regulated learning and academic achievement: An overview and analysis. In B. J. Zimmerman \& D. H. Schunk (Eds.), Self-regulated learning and academic achievement: Theoretical perspectives (pp. 1-38), Mahwah, NJ: Erlbaum.

Corresponding author: Eric Poitras, eric.poitras@utah.edu

Australasian Journal of Educational Technology (c) 2017.

Please cite as: Poitras, E., Doleck, T., Huang, L., Li, S., \& Lajoie, S. (2017). Advancing teacher technology education using open-ended learning environments as research and training platforms. Australasian Journal of Educational Technology, 33(3), 32-45. https://doi.org/10.14742/ajet.3498 